\title{
Allergen exposure, atopy and smoking as determinants of allergy to rats in a cohort of laboratory employees
}

\author{
P. Cullinan, A. Cook, S. Gordon, M.J. Nieuwenhuijsen, R.D. Tee, K.M. Venables, \\ J.C. McDonald, A.J. Newman Taylor
}

Allergen exposure, atopy and smoking as determinants of allergy to rats in a cohort of laboratory employees. P. Cullinan, A. Cook, S. Gordon, M.J. Nieuwenhuijsen, R.D. Tee, K.M. Venables, J.C. McDonald, A.J. Newman Taylor. (C)ES Journals Ltd 1999.

ABSTRACT: This study aimed to examine the relationship between exposure to rat urinary allergens, atopic status, smoking and the development of allergic symptoms and specific sensitization.

It is a case-referent analysis of a cohort of 342 newly employed laboratory animal workers. Cases comprised persons developing symptoms of laboratory animal allergy or a positive skin prick test to rat urinary allergens; each was matched with up to two asymptomatic referents. Subjects were assigned to categories of exposure based on measurements of airborne rat urinary allergens.

Of the cases, $80 \%$ reported that their symptoms started within 2 yrs of employment. The odds ratio (OR) for development of each symptom type (respiratory, eye or nose and skin) and of an immediate skin test reaction was increased in those with direct contact with rats. A gradient of increasing OR for the development of any such symptom across exposure categories was found; for respiratory symptoms and skin test reactions the $O R$ for subjects in the highest exposure category were lower than those in intermediate categories, a pattern attenuated when the analysis was confined to outcomes developing within 2 yrs of first exposure. Atopy increased the OR of most outcomes as did cigarette smoking, although there was no evidence of a relationship between smoking and the development of a specific skin test reaction.

In conclusion, allergen exposure was confirmed as the most important determinant of laboratory animal allergy; by implication, measures to reduce exposure may be the most effective means to reduce its incidence.

Eur Respir J 1999; 13: 1139-1143.
Dept of Occupational and Environmental Medicine, Imperial College School of Medicine (NHLI), London, UK.

Correspondence: P. Cullinan

Dept of Occupational and Environmental Medicine

Imperial College School of Medicine (NHLI)

Manresa Road

London SW3 6LR

UK

Fax: 441713518336

Keywords: Atopy

cohort study

exposure

laboratory animals

occupational asthma

smoking

Received: June 301998

Accepted after revision January 261999

Funding provided by the Health and Safety Executive, the National Asthma Campaign and the Royal Society.
Allergy to inhalable, animal-derived proteins is a common occupational health problem among employees working with small laboratory animals. In a prospective study of new staff at a large toxicological laboratory with several animal species, the incidence of clinically-diagnosed laboratory-animal allergy in the first year was $9 \%$ and that of specific immunoglobulin ( $\mathrm{Ig}) \mathrm{E}$ development $22 \%$ [1]. Figures from the surveillance of work-related and occupational respiratory disease (SWORD) national surveillance scheme indicate that laboratory animal proteins are the commonest high molecular weight cause of occupational asthma seen by chest and occupational physicians in the UK [2]; the annual incidence of new cases of laboratory animal asthma in the UK, estimated from the same source, is at least 188 per million exposed employees [3].

With the development of immunoassays [4] it has become possible to measure directly the relationship between intensity of exposure to airborne animal allergens and sensitization and allergic disease. This relationship has been studied in a cohort with occupational exposure to laboratory rats; in a previous report of the initial, cross-sectional phase [5] weak associations between allergic symptoms and rat urinary aeroallergen exposure, modified by atopic status were described. The present study describes the findings of a full longitudinal study, analysed using a nested case-referent approach.

\section{Methods}

\section{Definition of the cohort}

Employees at three large research establishments carrying out toxicological (site A) or basic sciences (sites B1 and B2) animal work were studied. A cohort $(n=355)$ was formed from all male and female employees working in areas with potential exposure to laboratory rats who had started work at these sites between January 1, 1986 and December 31, 1993 and had worked there for at least 1 month; the analyses are restricted to employees known not to have worked previously with laboratory animals. Fieldwork began in 1990 and continued with site visits at 6month intervals until the end of 1993, a total of seven visits to each site. Over $80 \%$ of those eligible and still employed attended at each visit.

One hundred and thirty-seven $(42 \%)$ employees were seen on seven occasions; 33, 18, 29, 25, 70 and 43 were seen on six, five, four, three, two and one occasion(s), 
respectively. Observation started at the date of first employment at the site and terminated when a subject became a case, left the site or was lost to follow-up; or at the end of the study. The median duration of observation of those who did not develop work-related symptoms or sensitization was 32 months, with an interquartile range of 26-50 months. Limited postal information was obtained from $88 \%$ of the 198 cohort members who had left the site before fieldwork started. Apart from a higher turnover of research scientists at site $\mathrm{A}$, there were no important differences in the occupations of those who were and were not seen during fieldwork. In the analyses only information from those who were surveyed during fieldwork have been used.

\section{Exposure measurements}

Individual work histories, including job titles since first employment at the site, were obtained at each visit, and updated at subsequent visits, by questionnaire. Detailed personal exposure measurements were carried out and have been described in full elsewhere [6]; briefly, 278 whole shift exposures to rat urinary aeroallergens, assayed by radioallergosorbent test inhibition were measured over 1 yr using an exposure-zone sampling technique. For the purposes of these analyses subjects were placed into one of four, approximately equal sized, exposure categories based on the whole-shift, geometric mean aeroallergen intensities of each exposure zone (table 1). Those in the lowest category, office workers and slideproduction staff, were not in direct contact with animals.

\section{Outcomes}

At each visit participants were asked to complete a questionnaire enquiring into symptoms and, if present, the date of their onset and relationship with work. Reported symptoms referable to the chest (tightness, wheeze or whistling or difficulty in breathing), eye (itching) or nose (itching, sneezing, running or blockage) and skin (itchy rash) were considered work-related if they improved at weekends or on absence from work for a week or more, or if they resulted from contact with laboratory rats. Only symptoms which were reported to have started after first

Table 1. - Exposure categories used in the analysis

\begin{tabular}{|c|c|c|c|c|}
\hline \multirow[t]{2}{*}{ Job title (site) } & \multirow[t]{2}{*}{$\mathrm{n}$} & \multirow[t]{2}{*}{ Category } & \multicolumn{2}{|c|}{$\begin{array}{l}\text { Rat urinary aeroallergen } \\
\text { exposure } \mu \mathrm{g} \cdot \mathrm{m}^{-3}\end{array}$} \\
\hline & & & GM & $95 \% \mathrm{CI}$ \\
\hline $\begin{array}{l}\text { Office staff }(\mathrm{A}), \\
\text { slide producer }(\mathrm{A})\end{array}$ & 80 & 1 (low) & 0.05 & $0.04-0.07$ \\
\hline Scientist (A) & 81 & 2 & 0.12 & $0.06-0.23$ \\
\hline $\begin{array}{l}\text { Scientist (B), } \\
\text { supervisor (A), } \\
\text { cage-cleaner (A), } \\
\text { post mortem (A) }\end{array}$ & 103 & 3 & 1.26 & $0.86-1.85$ \\
\hline $\begin{array}{l}\text { Animal technician } \\
\text { (A, B), cage- } \\
\text { cleaner (B) }\end{array}$ & 78 & 4 (high) & 30.36 & $21.67-42.55$ \\
\hline
\end{tabular}

GM: geometric mean; CI: confidence interval; A: toxicological site; B: basic sciences site. employment at the site (termed "new") were analysed. Specific IgE, on each occasion, was identified by skin prick tests with a dialysed extract of rat urine, a positive test being one with a mean weal diameter of $\geq 3 \mathrm{~mm}$ after subtraction of the response to a saline control. Where subjects were found to have a positive skin test reaction to rat urine at their first test, the date of conversion was taken to be halfway between the date of first employment and the visit date. Ninety-seven per cent of repeat skin prick tests were performed within 6 months of the preceding test.

Smokers were defined as persons who reported smoking $\geq 1$ cigarettes $\cdot$ day $^{-1}$ for as long as a year while employed at the site. Participants were considered atopic if, on skin prick testing at their first examination, they had at least one positive response ( $\geq 3 \mathrm{~mm}$ ) to three common inhalant allergens (Bencard, Brentford, UK): B2 grass pollens (4100), cat dander (3204) and Dermatophagoides pteronyssinus (2801).

\section{Subject selection and analysis}

A nested, matched case-referent analysis within the cohort is reported. Cases were those with new, work-related symptoms or a positive skin test to rat urine extract, their exposure category being determined by their work at the time of developing symptoms or at first detection of a positive skin test, regardless of how long they had been so employed. Referents, who at no time during the period of the study had work-related symptoms or a positive skin test to rat urine, were chosen, by computer, at random from those who were working at the time the case developed symptoms or a positive skin prick test and who had been employed for a similar (within 6 months) duration. Referents could be selected more than once; where available up to two were chosen for each case. Odds ratios and 95\% confidence intervals (CI) for each of the four exposure categories, adjusted for age, sex, site, atopic status and smoking were calculated using conditional logistic regression (EGRET statistical software; EGRET, Seattle, WA, USA) and including only those matched case-referent groups from whom full information was collected. Confidence intervals which did not include 1.00 were considered as statistically significant at the $5 \%$ level. Interaction between categories of allergen exposure and atopic status or smoking was examined using product variables (exposure category $\times$ atopic status/smoking) in the regression equation.

\section{Ethical approval}

The study was approved by the Ethics Committee of the Royal Brompton Hospital.

\section{Results}

Relevant characteristics of the participants, by case status, are shown in table 2. Cases did not differ greatly from referents in terms of age or sex distribution but were more frequently atopic and cigarette smokers. Cases of all types tended to be employed in the higher exposure categories. 
Table 2. - Characteristics of analysed subjects by case status

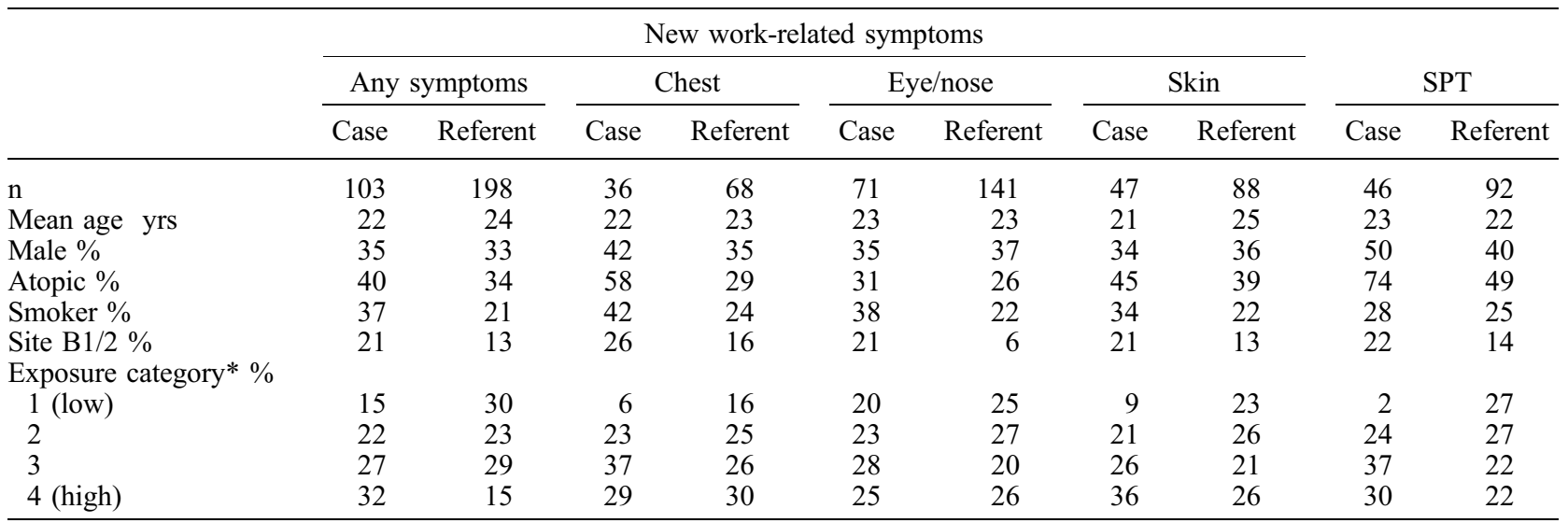

SPT: skin prick test which was positive to rat urinary allergen. *: exposure data were missing in a small proportion of subjects.

A total of 36 employees developed work-related chest symptoms, an incidence of 3.5 per 100 person years; the incidence rates of work-related eye/nose and skin symptoms were 7.3/100 person years $(n=84)$ and 4.8/100 person years $(n=59)$, respectively. A positive skin prick test to rat urinary allergens was measured in 54 employees, an incidence of 4.1 per 100 person years. Figure 1 indicates that the highest annual incidence of symptoms and of a positive skin test to rat urine was in the first 12 months and that some $80 \%$ had occurred within 2 yrs. This pattern was similar for all symptom types. The median length of employment before the development of new, work-related chest symptoms was 18 months compared to 12 months and 8 months for eye/nose and skin symptoms, respectively. Eleven cases, $31 \%$ of subjects with new chest symptoms, reported these without other symptoms, the percentages for skin and eye/nose symptoms were $35 \%(n=17)$ and $45 \%(n=33)$, respectively. Among cases with new, work-related chest symptoms, $46 \%$ had a positive skin test; for cases with eye/nose and skin symptoms the figures were 32 and $42 \%$. Conditional logistic regression (unadjusted) confirmed each of these percentages to be significantly higher $(p \leq 0.001)$ than among referents.

After adjustment for potential confounding exposures, subjects in exposure categories 2, 3 or 4 had a consistently higher odds ratio of developing any work-related symp-

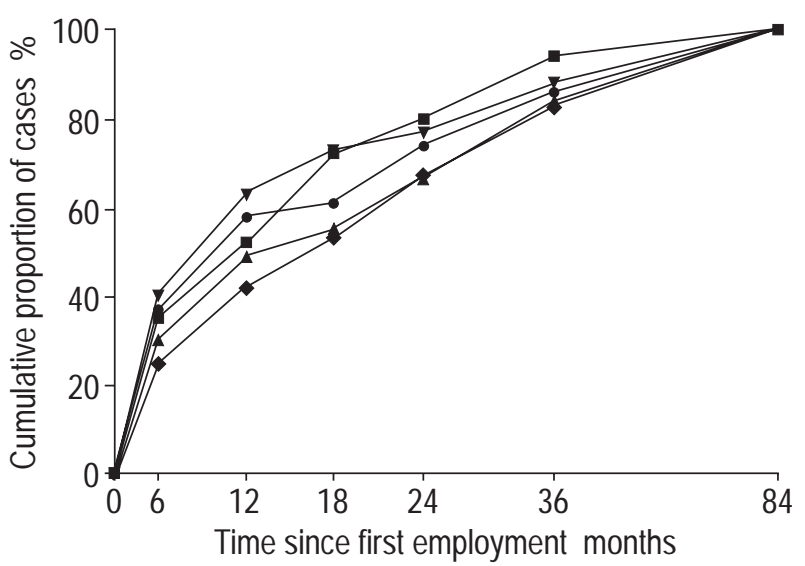

Fig. 1. - Latency of new, work-related symptoms or development of sensitization to rat urinary allergens. $\bullet$ : any; $\bullet$ : chest; $\boldsymbol{\Delta}:$ eye/nose; $\boldsymbol{\nabla}$ skin; $\mathbf{\square}$ : skin prick test. toms (odds ratio $2.6,95 \%$ CI $1.3-5.2$ ) or a positive skin prick test (odds ratio $14.5,95 \%$ CI $1.5-144$ ); this association remained, but was not statistically significant, when symptom types were examined separately. Adjusted odds ratios for atopic status and cigarette smoking were generally, but not consistently, raised. Subjects at site B had slightly increased risks of all outcomes, although these were not statistically significant. The odds ratios for each outcome were independent of age and sex. Only four employees with any work-related symptoms moved between jobs in different exposure categories during the period of follow-up; in each case after the onset of symptoms.

The exposure-response relationships were examined in more detail by separating the four exposure categories (table 3); atopy and cigarette smoking were retained as potentially confounding variables. Using all subjects in the analysis a weak relationship across the categories was found for cases with any of the three symptom types, and for eye or nose and skin symptoms separately. For subjects with chest symptoms and for those with positive skin tests the odds ratios in the highest exposure category were lower than those in intermediate categories. This pattern was less evident when the analysis was restricted to cases developing within 2 yrs of first employment (table 4), after which the odds ratios associated with each exposure category increased. Adjusted odds ratios for atopic status and smoking tended to be increased but they were generally small and less than those associated with allergen exposure. There was no significant interaction between allergen exposure and either atopic status or smoking.

Thirty-seven cases who reported one or more new, work-related symptoms also had a positive skin prick test to rat urine: $27(73 \%)$ were atopic; $12(32 \%)$ were cigarette smokers. Unadjusted odds ratios $(95 \% \mathrm{CI})$ associated with exposure in categories 2, 3 and 4 were 3.7 (0.3-39.8), 10.1 (1.2-87.4) and 12.6 (1.5-105), respectively. This trend remained, but was not statistically significant, after adjustment for atopy and smoking.

\section{Discussion}

This nested analysis of a cohort has confirmed an increased risk of allergic symptoms and specific sensitization 
Table 3. - Exposure-response relationships for four categories of exposure; independent odds ratio (OR) derived from conditional logistic regression, all cases

\begin{tabular}{|c|c|c|c|c|c|c|c|c|c|c|}
\hline \multirow{3}{*}{ Exposure category } & \multicolumn{8}{|c|}{ New work-related symptoms } & & \\
\hline & \multicolumn{2}{|c|}{ Any symptoms } & \multicolumn{2}{|c|}{ Chest } & \multicolumn{2}{|c|}{ Eye/nose } & \multicolumn{2}{|c|}{ Skin } & \multicolumn{2}{|c|}{ SPT } \\
\hline & OR & $95 \% \mathrm{CI}$ & OR & $95 \% \mathrm{CI}$ & OR & $95 \% \mathrm{CI}$ & OR & $95 \% \mathrm{CI}$ & OR & $95 \% \mathrm{CI}$ \\
\hline 1 (low) & 1 & & 1 & & 1 & & 1 & & 1 & \\
\hline 2 & 1.6 & $0.7-3.5$ & 1.9 & $0.3-13.1$ & 2.1 & $0.9-5.0$ & 3.7 & $0.8-17.0$ & 8.6 & $0.9-85.9$ \\
\hline 3 & 1.8 & $0.8-3.7$ & 3.5 & $0.7-18.7$ & 2.2 & $0.9-5.1$ & 4.9 & $1.0-25.4$ & 21.9 & $1.9-253$ \\
\hline 4 (high) & 3.0 & $1.4-6.2$ & 0.9 & $0.1-5.5$ & 2.5 & $1.0-6.3$ & 6.8 & $1.6-29.9$ & 12.3 & $1.1-143$ \\
\hline Atopy & 1.3 & $0.7-2.3$ & 5.2 & $1.9-16.9$ & 0.7 & $0.4-1.3$ & 1.2 & $0.5-2.8$ & 6.1 & $2.1-17.8$ \\
\hline Smoking & 3.3 & $1.7-6.2$ & 1.4 & $0.5-3.6$ & 1.7 & $0.9-3.3$ & 1.6 & $0.6-4.3$ & 0.8 & $0.3-2.2$ \\
\hline
\end{tabular}

SPT: skin prick test which was positive to rat urinary allergen; CI: confidence interval.

among those in direct contact with animals. Within the cohort there was a gradient of increasing odds ratios across four categories of increasing exposure intensity; this trend was made clearer when the analysis was confined to symptoms reported to have started within 2 yrs of first exposure. The high incidence of symptoms and of specific sensitization in this period may in part reflect the relatively short period of follow-up in the cohort, and the approach used for assigning a date of onset to prevalent positive skin prick tests. The presence of specific $\operatorname{IgE}$ antibodies to rat allergens prior to first occupational exposure has been described elsewhere [7] and may have further inflated these estimates of incidence. Others however have reported that the incidence of allergic symptoms or of specific IgE development [1] among laboratory animal employees is highest in the period of early exposure; a similar pattern has been demonstrated among workers encountering other occupational allergens [8-11].

The present findings confirm the increase in risk among atopic subjects noted by others $[1,7,8,12,13]$ but do not indicate any statistically significant interaction between atopic status and allergen exposure. The odds ratios associated with allergen exposure were generally higher than those for atopic status, indicating that the maintenance of low levels of exposure remains of primary importance in the prevention of occupational allergic disease in these employees. In this study, allergic symptoms, but not $\operatorname{IgE}$ sensitization, were also more common among cigarette smokers although the estimates were statistically significant only for eye/nose symptoms. Sex and age did not exert independent effects on the risk of any of the outcomes.
When all cases were examined, the risk estimates for new chest symptoms and positive skin tests to rat urine were lower among employees in the highest exposure categories than for those with intermediate levels of exposure. This may reflect a survival bias among those with these particular outcomes, although there was no evidence that cohort members with the highest exposure had left either site at an increased rate; furthermore, the matching of cases and referents on duration of exposure should have reduced the magnitude of any such bias. Differential misclassification of outcomes, whereby a greater proportion of chest symptoms reported by those in intermediate-exposure categories had a nonallergic basis (a bias lessened by confining the analysis to those with early disease onset), would not explain the pattern found with positive skin tests. The presence of a positive skin test to rat allergens in a small proportion of employees prior to first employment [13] may have weakened the exposure-response relationships, but assuming them to be equally distributed across the categories of subsequent occupational exposure, is unlikely to have produced any bias. An alternative explanation lies in the nature of the exposure estimates which reflect mean, whole-shift intensities of allergen exposure and take only indirect account of short-term, high intensity ("peak") exposures which may be important (e.g. in scientists) in the induction of allergic disease; and nor did they allow for any impact of personal respiratory protection. A third possible explanation is the phenomenon of high-dose tolerance whereby very high allergen exposure induces deletion of allergen-specific Tcells. Such a mechanism has been postulated to explain the disappearance, by adulthood, of infant responses to

Table 4. - Exposure-response relationships for four categories of exposure; independent odds ratios (OR) derived from conditional logistic regression, cases occurring within 2 yrs of first employment

\begin{tabular}{|c|c|c|c|c|c|c|c|c|c|c|}
\hline \multirow{3}{*}{ Exposure category } & \multicolumn{8}{|c|}{ New work-related symptoms } & & \\
\hline & \multicolumn{2}{|c|}{ Any symptoms } & \multicolumn{2}{|c|}{ Chest } & \multicolumn{2}{|c|}{ Eye/nose } & \multicolumn{2}{|c|}{ Skin } & \multicolumn{2}{|c|}{ SPT } \\
\hline & OR & $95 \% \mathrm{CI}$ & OR & $95 \% \mathrm{CI}$ & OR & $95 \% \mathrm{CI}$ & OR & $95 \% \mathrm{CI}$ & OR & $95 \% \mathrm{CI}$ \\
\hline 1 (low) & 1 & & 1 & & 1 & & 1 & & 1 & \\
\hline 2 & 2.1 & $0.8-5.7$ & 2.4 & $0.2-38.2$ & 3.0 & $0.8-10.9$ & 2.9 & $0.5-16.6$ & 3.0 & $0.3-29$ \\
\hline 3 & 3.5 & $1.4-8.6$ & 5.5 & $0.5-65.1$ & 3.7 & $1.1-12.2$ & 2.8 & $0.6-14.4$ & 6.0 & $0.6-57.1$ \\
\hline 4 (high) & 5.7 & $2.2-14.6$ & 4.6 & $0.3-77.4$ & 3.2 & $0.9-11.5$ & 4.9 & $0.9-27.9$ & 5.7 & $0.6-53$ \\
\hline Atopy & 1.1 & $0.7-2.6$ & 2.7 & $0.8-9.7$ & 0.4 & $0.2-1.0$ & 1.3 & $0.5-3.3$ & 2.9 & $1.1-7.9$ \\
\hline Smoking & 2.8 & $1.3-5.9$ & 3.4 & $0.6-19.4$ & 3.9 & $1.5-9.9$ & 1.4 & $0.5-3.6$ & 0.9 & $0.2-3.1$ \\
\hline
\end{tabular}

SPT: skin prick test which was positive to rat urinary allergen; CI: confidence interval. 
dietary allergens [14], but has not otherwise been shown to act in human responses to inhaled allergens.

The associations with allergen exposure reported in this study are broadly in keeping with the author's earlier report [4] which included less than half of the cases analysed here, and with the findings of cross-sectional surveys in which indirect $[7,11]$ or direct [13] assessments of exposure were made. Longitudinal studies of occupational allergic disease are few and this is the first study of laboratory animal allergy to incorporate direct exposure measurements. Using the more common cross-sectional approach, exposure-response relationships may be masked [15] or even inverted [16], probably by selection pressures. Only by restricting their analysis to those with $<4$ yrs exposure were Hollander et al. [13] able to demonstrate an association between allergen exposure and allergic disease or sensitization in their population. In order to reduce the potential for survival bias the present cohort was designed to include only newly employed workers and limited the analysis to those without previous occupational exposure to laboratory animals. A longitudinal, prospective design such as this, requiring repeated assessments over a period of several years, can be expensive and time-consuming. The case-referent analysis presented above produced results very similar to those obtained by an unpublished person-yrs analysis of the same information. Future studies of occupational asthma might efficiently be based on a retrospective analysis of cases and referents, ascertained within a defined population and with careful enquiries to identify evidence of survivor bias.

In conclusion, this study confirmed allergen exposure as the most important determinants of laboratory animal allergy. Measures to reduce exposure may be the most effective means to reduce its incidence.

\begin{abstract}
Acknowledgements. Field work for this study was performed by R. Blanks, J. Clark, M. Divitini, B. Fitzgerald, J. Foster, B. Graneek, J. Harris, J. Hayes, C. Hogg, G. Lamond, K. Sullivan and J. Welch. D. Lowson assisted with the early statistical analyses. The authors are very grateful to the participants and management staff of the study sites.
\end{abstract}

\section{References}

1. Botham PA, Lamb CT, Teasdale EL, Bonner SM, Tomenson JA. Allergy to laboratory animals: a followup study of its incidence and of the influence of atopy and pre-existing sensitisation on its development. Occup Environ Med 1995; 52: 129-133.
2. Ross D, Sallie B, McDonald JC. SWORD '94: surveillance of work-related and occupational respiratory disease in the United Kingdom. Occup Med 1995; 45: 175-178.

3. Meredith S. Reported incidence of occupational asthma in the United Kingdom, 1989-1990. J Epidemiol Comm Health 1993; 47: 459-463.

4. Gordon S, Tee RD, Nieuwenhuijsen MJ, Lowson D, Harris J, Newman Taylor AJ. Measurement of airborne rat urinary allergen in an epidemiological study. Clin Exp Allergy 1994; 24: 1070-1077.

5. Cullinan P, Lowson D, Nieuwenhuijsen MJ, et al. Workrelated symptoms, sensitisation and estimated exposure in workers not previously exposed to laboratory rats. Occup Environ Med 1994; 51: 589-592.

6. Nieuwenhuijsen MJ, Gordon S, Tee RD, Venables KM, McDonald JC, Newman Taylor AJ. Exposure to dust and rat urinary aeroallergens in research establishments. $O c$ cup Environ Med 1994; 51: 593-596.

7. Aoyama K, Ueda A, Manda F, Matsushita T, Ueda T, Yamauchi C. Allergy to laboratory animals: an epidemiological study. Br J Ind Med 1992; 49: 41-47.

8. Juniper CP, How MJ, Goodwin BFJ, Kinshott AK. Bacillus subtilis enzymes: a seven year clinical, epidemiological and immunological study of an industrial allergen. J Soc Occup Med 1977; 27: 3-12.

9. Butcher BT, Jones RN, O'Neil CE, et al. Longitudinal study of workers employed in the manufacture of toluene diisocyanate. Am Rev Respir Dis 1977; 116: 411-421.

10. Venables KM, Daily MB, Nunn AJ, et al. Smoking and occupational allergy in a platinum refinery. $\mathrm{Br}$ Med $\mathrm{J}$ 1989; 299: 939-942.

11. Bryant DH, Boscato LM, Mboloi PN, Stuart MC. Allergy to laboratory animals among animal handlers. Med J Aust 1995; 163: 415-418.

12. Fuortes U, Weih L, Jones ML, et al. Epidemiologic assessment of laboratory animal allergy among university employees. Am J Indust Med 1996; 29: 67-74.

13. Hollander A, Heederik D, Doekes G. Respiratory allergy to rats, exposure-response relationships in laboratory animal workers. Am J Respir Crit Care Med 1997; 155: 562 567.

14. Holt PG, O'Keefe PO, Holt BJ, et al. T-cell "priming" against environmental allergens in human neonates: sequential deletion of food antigen reactivity during infancy with concomitant expansion of responses to ubiquitous inhalant allergens. Pediatr Allergy Immunol 1995; 6: 8590.

15. Cockcroft A, Edwards J, McCarthy P, Andersson N. Allergy in laboratory animal workers. Lancet 1981; i: 827-830.

16. Venables KM, Tee RD, Hawkins ER, et al. Laboratory animal allergy in a pharmaceutical company. $B r J$ Ind Med 1988; 45: 660-666. 